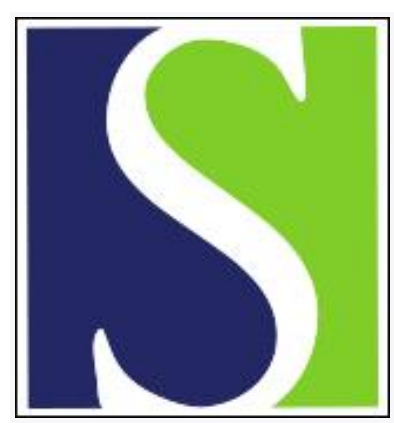

Scand J Work Environ Health 1986;12(4):265-268

https://doi.org/10.5271/sjweh.2141

Issue date: Aug 1986

A clinical assessment of seventy-eight cases of hand-arm vibration syndrome.

by Taylor W, Ogston SA, Brammer AJ

This article in PubMed: www.ncbi.nlm.nih.gov/pubmed/3775311

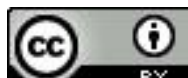




\title{
A clinical assessment of seventy-eight cases of hand-arm vibration syndrome
}

\author{
by William Taylor, DSc, MD, FRCP, FFOM, ${ }^{1}$ Simon A Ogston, MA, MSc, ${ }^{1}$ \\ Anthony J Brammer, BSc, $\mathrm{PhD}^{2}$
}

\begin{abstract}
TAYLOR W, OGSTON SA, BRAMMER AJ. A clinical assessment of seventy-eight cases of hand-arm vibration syndrome. Scand $J$ Work Environ Health 12 (1986) 265-268. After the obtainment of an occupational history the following objective tests were carried out: esthesiometry, light touch, pain, temperature appreciation, Tinel's and Phalen's test, grip strength, Allen's test, and cold provocation $\left(10-12^{\circ} \mathrm{C}\right.$ for $1 \mathrm{~min}$ ). The 78 subjects were categorized (Taylor-Pelmear classification) according to the number, severity, and extent of the blanching attacks; sensory loss; musculoskeletal complaints; and interference with work and domestic and social activities. Four of the subjects had unequal hand assessments. It was not possible to correlate stage assessment with the objective tests on an individual basis. On a group basis, staging correlated with esthesiometry using the improved designs of Carlson et al. Cold provocation produced white finger attacks in only $50 \%$ of the cases. In some work processes (road ripping) of the subjects, damage to digital arteries and nerves was confined to the thumb and index and middle fingers. Four subjects had advanced tissue necrosis of the fingertips resulting from the use of hand-held pneumatic percussive tools. There was no evidence to support the view that the hand-arm vibration syndrome affects the central autonomic nervous system.
\end{abstract}

Key terms: esthesiometer, correlation, objective tests, staging, white fingers.

In attacks of white finger there has been no convincing reproducible test for measuring the pathological changes in digital arteries. An alternative approach is to attempt to measure sensory changes in the fingers; it requires instrumentation to detect changes in the performance of the sensory transducers - the mechanoreceptors in the hairless skin of the hand and digits known to respond to pressure, instrument edges, and vibration. In addition to the simple, clinical sensory tests used by the early clinicians (light touch, pain, and temperature appreciation), esthesiometry and vibrotactile finger-pulp perception thresholds are now receiving attention for the detection of early neurological changes.

In this paper an attempt has been made to correlate early clinical neurological tests with stage assessments arrived at from a subjective history and a general medical examination. The purpose of this comparison was to establish which objective tests are worthy of further study and application.

\section{Subjects and methods}

In the interval from August 1981 to August 1984, 78 claimants for Common Law compensation in the United Kingdom were examined and assessed by an

\footnotetext{
1 Department of Community Medicine, University of Dundee, Dundee, Scotland.

2 Division of Physics, National Research Council of Canaca, Ottawa, Canada.
}

Reprint requests to: Professor W Taylor, Nether Banks, Watten, Wick, Caithness, KW1 5XJ, Scotland. examiner (WT). From each subject the following variables were recorded, provided their finger temperature did not fall below $30^{\circ} \mathrm{C}$ and they had not been exposed to vibration for a minimum of $24 \mathrm{~h}$ : (i) esthesiometry (two-point and depth sense): all digits, excluding thumbs; (ii) light touch (cotton wool): all digits, including thumbs; (iii) pain (sharp pin): all digits, including thumbs; (iv) temperature (metal probe): all digits, including thumbs; (v) Tinel's and Phalen's tests (for carpal tunnel syndrome), flexor retinaculum; (vi) grip strength (sphygmomanometer cuff); (vii) Allen's test (for blood vessel abnormalities); (viii) cold provocation $\left(10-12^{\circ} \mathrm{C}\right.$ for $\left.1 \mathrm{~min}\right)$; and (ix) condition assessment (stationary/improving/deteriorating).

The following laboratory tests were conducted, but detailed results of these tests are not included in this report: full blood count, erythrocyte sedimentation rate, rheumatoid fixation tests, antinuclear antibodies, C-reactive protein, cryoglobulin, and urine analysis for proteinuria, casts and hydroxyproline. The patient's age, smoking habits, total vibration exposure, latency interval, and vibration process were inquired about. A general medical examination was conducted, and a verbal occupational history was obtained that included the number, severity, and extent of blanching attacks and sensory loss and its influence on the subject's domestic and social activities, and on his work and hobbies. On the basis of this information the claimants were stage-assessed according to the Taylor-Pelmear classification for vibration-induced white finger (VWF) (3).

The distribution of the assessed stage of VWF, objective tests, and esthesiometric measurements was ob- 
tained, and the relationships between these variables were investigated. The proportion of subjects in each stage who would have been identified by the objective tests and by esthesiometry was calculated to find the sensitivity of the tests in detecting individuals with VWF.

\section{Results}

\section{Subjects}

The age distribution of the claimants is shown in table 1. The clinical staging for 74 subjects in whom both hands had equal stages of VWF is given in table 2 . Four of the claimants had unequal assessments, and their staging is not included in this table. In view of the asymmetrical staging in these cases, the results of objective tests are presented separately for the right and left hands. The smoking habits of the vibration-exposed workers are given by VWF stage in table 3 . All four cases with tissue necrosis (stage 4TN) were smokers, the mean daily consumption of cigarettes being 23 (range 20 to 40 ) over a period of 27 years (range $20-32$ years).

Table 1. Number of cases by age.

\begin{tabular}{lccccccc}
\hline & \multicolumn{6}{c}{ Age group (years) } & Total \\
\cline { 2 - 7 } Number & $25-29$ & $30-39$ & $40-49$ & $50-59$ & $60-65$ & \\
\cline { 2 - 8 } & 1 & 13 & 29 & 30 & 5 & 78 \\
\hline
\end{tabular}

Table 2. Number and percentage of cases by the TaylorPelmear stage of vibration-induced white finger.

\begin{tabular}{|c|c|c|c|c|c|c|c|c|}
\hline & \multicolumn{7}{|c|}{ Taylor-Pelmear stage } & \multirow{2}{*}{ Total } \\
\hline & \multicolumn{2}{|r|}{1} & \multicolumn{2}{|r|}{2} & \multicolumn{2}{|r|}{3} & $4 \mathrm{TN}^{\mathrm{a}}$ & \\
\hline & $N$ & $\%$ & $\mathbf{N}$ & $\%$ & $\mathbf{N}$ & $\%$ & N \% & 18 \\
\hline Cases & 1 & 1.4 & 27 & 36.5 & 42 & 56.8 & 45.3 & $7494.9^{b}$ \\
\hline
\end{tabular}

a $\mathrm{TN}=$ with tissue necrosis.

b Four cases not included - unequal hands.

Table 3. Number and percentage of subjects who were smokers, exsmokers and nonsmokers by stage of vibrationinduced white finger (VWF).

\begin{tabular}{|c|c|c|c|c|c|c|c|}
\hline \multirow{2}{*}{ VWF stage } & \multicolumn{2}{|c|}{ Smokers } & \multicolumn{2}{|c|}{$\begin{array}{c}\text { Ex- } \\
\text { smokers }\end{array}$} & \multicolumn{2}{|c|}{$\begin{array}{c}\text { Non- } \\
\text { smokers }\end{array}$} & \multirow{2}{*}{$\begin{array}{c}\text { Tota } \\
\text { (N) }\end{array}$} \\
\hline & $N$ & $\%$ & $N$ & $\%$ & $N$ & $\%$ & \\
\hline $\begin{array}{l}1 \\
2 \\
3 \\
3+ \\
4 \\
1+2+3+4\end{array}$ & $\begin{array}{r}1 \\
11 \\
15 \\
5 \\
4 \\
34\end{array}$ & $\begin{array}{r}100 \\
42 \\
83 \\
83 \\
100 \\
46\end{array}$ & $\begin{array}{l}\overline{8} \\
11 \\
\overline{-} \\
21\end{array}$ & $\begin{array}{r}0 \\
30 \\
31 \\
0 \\
0 \\
28\end{array}$ & $\begin{array}{r}-8 \\
10 \\
1 \\
-19\end{array}$ & $\begin{array}{r}0 \\
30 \\
28 \\
17 \\
0 \\
26\end{array}$ & $\begin{array}{r}1 \\
27 \\
36 \\
6 \\
4 \\
74\end{array}$ \\
\hline
\end{tabular}

a Four cases not included - unequal hands.
Sense of light touch, pain, and temperature and grip force

The results of the objective tests for the sense of touch, pain, and temperature and for grip force are shown in table 4 according to the VWF stage. The percentage of normal values found in advanced cases of the syndrome serve as an indication of the value of the tests for diagnostic purposes.

\section{Esthesiometry}

Table 5 shows the mean, standard deviation, and number of readings obtained with the two-point and depth sense esthesiometers, by disease stage. The results are given in terms of the linear dimension along the block from the commencement of the gap or step. In both hands there was a general increase in the mean score with advancing stage. The results obtained by Carlson et al in 10 unexposed male referents are shown with the proportion of people in the present group who exceeded the values of these normals (1). The correlations between the results of the esthesiometry and those of the classical neurological tests for light touch, pain, and temperature are given in table 6 . Also included is the correlation with the Taylor-Palmear staging.

\section{Cold provocation}

Immersing both hands in cold water at a temperature of $10-12^{\circ} \mathrm{C}$ for $1 \mathrm{~min}$ resulted in finger blanching in 40 cases $(51.3 \%)$ and blue, cyanotic fingers but no blanching in 38 cases $(48.7 \%$ ). No attempt was made during the test to reduce central body core temperature.

\section{Discussion}

\section{Touch, pain and temperature}

The results for the of touch, pain, and temperature sensation tests are expressed at the time of examination as normal or abnormal responses to cotton wool, pinpricks, and a temperature probe. The light touch test performed on 78 pairs of hands was normal for 16 right and left hands (table 4). As a diagnostic test for the hand-arm vibration syndrome it failed. The sharp pin (pain test) showed an improvement to seven normal responses, and the temperature appreciation test to four normal responses. All 46 stage $3+4 \mathrm{TN}$ cases had abnormal responses to a raised temperature probe. Therefore, for diagnostic test efficiency, the order is temperature, pain, and then light touch. A similar order was found in a survey of workers using pneumatic chipping and grinding hand tools in the United States (4).

\section{Esthesiometry}

The results of three determinations for each digit of both hands with the two Carlson et al blocks (two point, block $\mathrm{C}$; depth sense, block $\mathrm{A}$ ) have been sum- 
Table 4. Number of hands with normal sensory responses to light touch (LT), pain, and temperature (temp) and with a normal hand grip by stage of vibration-induced white finger (VWF).

\begin{tabular}{|c|c|c|c|c|c|c|c|c|c|c|}
\hline \multirow{2}{*}{ VWF stage } & \multicolumn{4}{|c|}{ Right hand } & \multicolumn{4}{|c|}{ Left hand } & \multicolumn{2}{|c|}{ Total hands } \\
\hline & LT & Pain & Temp & Grip & LT & Pain & Temp & Grip & Right & Left \\
\hline 0 & 2 & 2 & 2 & 1 & - & - & - & - & 2 & - \\
\hline 1 & - & - & - & 1 & 1 & 1 & 1 & 1 & 1 & 1 \\
\hline 2 & 9 & 4 & 2 & 14 & 10 & 5 & 3 & 17 & 28 & 30 \\
\hline 3 & 5 & 1 & - & 4 & 5 & 1 & - & 6 & 37 & 37 \\
\hline $3+$ & - & - & - & 2 & - & - & - & 1 & 6 & 6 \\
\hline 4 & - & - & - & - & - & - & - & - & 4 & 4 \\
\hline
\end{tabular}

Table 5. Mean and standard deviation for two-point discrimination and depth sense by stage of vibration-induced white finger (VWF). The number and percentage of abnormal hands are also tabulated, the normal limit being taken as the mean $+1 S D$ of unexposed males reported by Carlson et al (1)

\begin{tabular}{|c|c|c|c|c|c|c|c|c|c|}
\hline \multirow{3}{*}{ WWF stage } & \multirow{3}{*}{$N$} & \multicolumn{4}{|c|}{ Two-point (cm) } & \multicolumn{4}{|c|}{ Depth sense $(\mathrm{cm})$} \\
\hline & & \multirow{2}{*}{ Mean } & \multirow{2}{*}{$\mathrm{SD}$} & \multicolumn{2}{|c|}{ Abnormals } & \multirow{2}{*}{ Mean } & \multirow{2}{*}{$\mathrm{SD}$} & \multicolumn{2}{|c|}{ Abnormals } \\
\hline & & & & $N$ & $\%$ & & & $N$ & $\%$ \\
\hline \multicolumn{10}{|l|}{ Right hand } \\
\hline $\begin{array}{l}0 \\
1 \\
2 \\
3 \\
3+ \\
4\end{array}$ & $\begin{array}{r}2 \\
1 \\
28 \\
37 \\
6 \\
4\end{array}$ & $\begin{array}{c}4.25 \\
11.0 \\
7.62 \\
8.78 \\
10.33 \\
10.25\end{array}$ & $\begin{array}{l}0.35 \\
0 \\
1.80 \\
1.99 \\
2.25 \\
1.04\end{array}$ & $\begin{array}{r}- \\
1 \\
16 \\
27 \\
6 \\
4\end{array}$ & $\begin{array}{c}0 \\
100 \\
57.1 \\
73.0 \\
100 \\
100\end{array}$ & $\begin{array}{l}3.5 \\
9.0 \\
6.26 \\
7.34 \\
9.33 \\
8.0\end{array}$ & $\begin{array}{l}0 \\
0 \\
2.0 \\
2.06 \\
2.99 \\
2.16\end{array}$ & $\begin{array}{r}- \\
1 \\
20 \\
33 \\
6 \\
4\end{array}$ & $\begin{array}{c}0 \\
100 \\
71.4 \\
89.2 \\
100 \\
100\end{array}$ \\
\hline $\begin{array}{l}\text { Carlson et al } \\
\text { normals }\end{array}$ & 10 & 5.33 & 1.65 & - & 0 & 3.31 & 1.24 & - & 0 \\
\hline \multicolumn{10}{|l|}{ Left hand } \\
\hline $\begin{array}{l}0 \\
1 \\
2 \\
3 \\
3+ \\
4\end{array}$ & $\begin{array}{r}-1 \\
30 \\
37 \\
6 \\
4\end{array}$ & $\begin{array}{l}4.5 \\
7.32 \\
8.82 \\
9.05 \\
9.12\end{array}$ & $\begin{array}{l}0 \\
1.80 \\
1.80 \\
3.51 \\
2.84\end{array}$ & $\begin{array}{r}- \\
15 \\
32 \\
5 \\
3\end{array}$ & $\begin{array}{c}5 \\
50.0 \\
86.5 \\
83.3 \\
75.0\end{array}$ & $\begin{array}{l}4.0 \\
5.95 \\
7.55 \\
8.55 \\
7.5\end{array}$ & $\begin{array}{l}0 \\
1.87 \\
1.96 \\
3.71 \\
2.65\end{array}$ & $\begin{array}{r}1 \\
25 \\
36 \\
6 \\
4\end{array}$ & $\begin{array}{c}0 \\
100 \\
83.3 \\
97.3 \\
100 \\
100\end{array}$ \\
\hline $\begin{array}{l}\text { Carlson et al } \\
\text { normals }\end{array}$ & 10 & 5.34 & 1.65 & . & & 2.88 & 1.0 & . & \\
\hline
\end{tabular}

Table 6. Rank correlations between the results of esthesiometry. Taylor-Pelmear staging, and the results of other sensory tests $(N=78$ cases $)$.

\begin{tabular}{|c|c|c|c|c|}
\hline \multirow{2}{*}{ Correlation with } & \multicolumn{2}{|c|}{ Right hand } & \multicolumn{2}{|c|}{ Left hand } \\
\hline & Two-point & Depth sense & Two-point & Depth sense \\
\hline $\begin{array}{l}\text { Taylor-Pelmear stage } \\
\text { Light touch } \\
\text { Pain } \\
\text { Temperature }\end{array}$ & $\begin{array}{l}0.42 \\
0.48 \\
0.37 \\
0.30\end{array}$ & $\begin{array}{l}0.33 \\
0.53 \\
0.34 \\
0.31\end{array}$ & $\begin{array}{l}0.40 \\
0.43 \\
0.28 \\
0.28\end{array}$ & $\begin{array}{l}0.36 \\
0.51 \\
0.31 \\
0.30\end{array}$ \\
\hline
\end{tabular}

marized in table 5 (mean longitudinal values in centimeters). The means and standard deviations for the discrimination threshold values for males given by Carlson et al are also shown in this table. On the assumption that a mean plus one standard deviation represents the upper limit of normality, there is significant correlation with staging in both the two-point and the depth-sense tests on a group basis. To test the correlation on an individual basis, we examined the readings from the 10 most severe cases (including the four tissue necrosis cases). Hence it was found that one stage 3 + case had normal esthesiometry readings from one hand (case 17) and a stage $4 \mathrm{TN}$ case (case 74) similar- ly a normal two-point threshold in one hand. Therefore in this series the esthesiometry tests failed on an individual basis.

Two factors are operating that could explain these variations: (i) the digital artery damage may be proceeding independently of the nerve damage, and (ii) there is individual variation in the work process with hands receiving unequal vibration dosage. In copper swaging, for example, it is common to find a worker holding with the dominant hand (right, in case 17) and using a reduced grip with the left (which possessed normal two-point and dense-sense perception in case 17). Nevertheless the results are encouraging in that the 
most severe cases of the syndrome showed test results at the extreme end of the block, with readings of 14 $\mathrm{cm}$ on both two-point and depth-sense discrimination.

\section{Generalized neurovegetative symptoms}

Contrary to reports in the Russian and Japanese literature, we found no evidence in our advanced cases to confirm the involvement of the central autonomic nervous system, apart from one subject reporting mild hyperhidrosis of the hands and one reporting pain and stiffness in one elbow joint. There were no complaints in this series of headache, fatigue, irritability, vertigo, increased hand tremor, chest pains, sleep disturbance, or impotency. Therefore, in the United Kingdom, where subjects are exposed to vibration in a variety of work processes, it is difficult to accept that "vibration disease"' is to be considered a systemic disorder induced by hand-arm vibration through the central nervous system (2). In our advanced cases no disturbance of the heart, the brain, or the endocrine system was reported as a result of exposure to vibration.

\section{Distribution of pathological changes}

In some work processes (road repairing and gas distributing, both requiring the use of percussive, pneumatic tools) damage to digital arteries and nerves is confined to the thumb and the index and middle fingers of both hands. Digits 4 and 5 appear to escape, a phenomenon emphasizing the importance of the handtool coupling. In our series, digits 4 and 5 did not suffer from blanching attacks and had normal sensory tests in some pneumatic tool operators. Three of the four reported cases of tissue necrosis were asociated with work processes using percussive, pneumatic tools. The fourth case was a copper swager. In these four cases there was no evidence in the medical examinations and laboratory tests of generalized arterial or connective tissue disease (scleroderma) to account for the advanced symptomatology of tissue necrosis.

\section{Conclusions}

1. On an individual basis, it was not possible to correlate stage assessment, based on the results of a medi- cal examination and data on subjective occupational history, and the symptomatology of the hand-arm vibration syndrome with the old type of objective clinical tests of sensory loss, loss of pain, and temperature appreciation. The correlation of these three tests with staging follows the order temperature appreciation, loss of pain, and sensory loss (by the cotton-wool test).

2. On a group basis, the improved esthesiometry design of Carlson et al showed significant correlation with staging for subjects at the severe end of the hand-arm vibration syndrome, ie, stages 2,3 , and 4 .

3. As employed in this investigation, cold provocation produced white finger attacks in only $50 \%$ of the cases. This finding demonstrates that factors other than a cold stimulus are required to initiate a VWF attack, eg, core body temperature, vascular tone, emotional state.

4. There was no evidence in this series to confirm the involvement of the central autonomic nervous system in the hand-arm vibration syndrome.

5. In some work processes, separate stage assessments are required for each hand. In this series, an unequal stage classification was given to the hands of four workers. The potential for unequal hand staging will have to be taken into account in plans for litigation in compensation cases.

\section{References}

1. Carlson WS, Samueloff S, Taylor W, Wasserman DE. Instrumentation for measurement of sensory loss in the fingertips. J Occup Med 21 (1979) 260-264.

2. Gemne $G$, Taylor $W$, ed. Hand-arm vibration and the central autonomic nervous system. J Low Freq Noise Vib 1 (1983): special issue.

3. Taylor W, Pelmear PL, ed. Vibration white finger in industry. Academic Press, London 1975, p XXI.

4. Wasserman D, Taylor W, Behrens V, Samueloff S, Reynolds D. Vibration white finger disease in US workers using chipping and grinding hand tools: I Epidemiology. US Department of Health and Human Services, National Institute for Occupational Safety and Health, Cincinnati, OH 1982. (DHHS/NIOSH tech rep no 82-118). 